\title{
Detection of Gene Expression from Vitis by Real Time Quantitative RT-PCR
}

\author{
Quan Zhao \\ College of Chinese Traditional Medicine Science, Jilin Agricultural Science and Technology College, Jilin, \\ 132109
}

Keywords: real time quantitative RT-PCR, Vitis amurensis Rupr, gene expression

\begin{abstract}
In this experiment, Vitis "shuangfeng” is used as the test materials to study gene expressed modes of 12 enzyme genes involved in the biosynthesis of phenolic compounds from skin in different growth time by real time quantitative reverse transcription-polymerase chain reaction (RT-PCR), and the relative expression of gene was calculated by $2^{-\Delta \Delta C t}$ value. The results showed the expressed patterns of genes were different from 2 weeks to maturity after flowering. The expressed level of PAL, CHS3, F3H2, UFGT, OMT and GST showed an upward trend. The expressed level of CHI1, DFR and LDOX showed a downward trend from 2 to 8 weeks after flowering, then began upward, and the highest expression level was in maturity. The expressed level of ANR, LAR1 and LAR2 showed a downward trend to maturity in fruit growth time.
\end{abstract}

\section{Introduction}

Studying the differences in gene expression of cells or individuals at different developmental stages or in different growth conditions is an important part of studying molecular regulation. The main methods to study the differences in gene expression are Northern blotting, dot blotting, differential display (DD-PCR), oligonucleotide microarrays, cDNA arrays and real-time quantitative [RT-PCR]. Real-time fluorescence quantitative PCR is a nucleic acid quantification technique developed on the basis of ordinary PCR qualitative technology. It uses the change of fluorescence signal to detect the change of amplification products in each cycle of PCR amplification reaction in real time. Through the $\mathrm{Ct}$ value and the standard curve Analysis Quantitatively analyze the starting template. It has the characteristics of high sensitivity, specificity and reliability, selectivity to DNA template, multiple reaction, high automation, no pollution, real-time and accuracy. At present, it is widely used in the differential expression of gene and transgene in crops Research, such as GMO testing. In this study, we used real-time fluorescence quantitative PCR to study the effects of phenylalanine ammonia-lyase (PAL), chalcone synthase (CHS3), chalcone Isomerase (CHI1), flavonoid 3'-hydroxylase (F3H2), flavanone 4-reductase (DFR), leucovorin dioxygenase (LDOX), glucose-flavonoid 3-O (UFGT), O-methyltransferase (OMT), glutathione S-transferase (GST) and anthocyanidin reductase (ANR) In the pericarp expression differences, by calculating the $2-\Delta \Delta \mathrm{Ct}$ value to determine the relative expression of genes in different periods, in order to further study the grape phenolics biosynthesis to provide reference and reference.

\section{Materials and Methods}

Mountain grape varieties Shuangfeng. The sampling time was 2 weeks, 4 weeks, 6 weeks after anthesis, 8 weeks after anthesis, the color changing period (all coloration less than 5\%), 10\% coloration, 50\% coloration, all coloration, maturity period 9 times, 1,2,3,4,5,6,7,8,9. Select the same growing 5 to 10 as a block, a total of 3 blocks. From each group, select the results of the growth of robust branches, ear size, direction consistent with the 10 ears, from the selection of 100 disease-free fruit, hand-separated peel, liquid nitrogen quick-frozen, $-80{ }^{\circ} \mathrm{C}$ cryopreservation, spare.

Grape peel RNA extraction reference temperature Pengfei CTAB method [2].

According to the full-length sequences of Gene Bank PAL, CHS3, CHI1, F3H2, DFR, LDOX, OMT, UFGT, GST, ANR, 18S rRNA and KyActin1, PCR amplification primers were designed by 
Primer 5.0 (see Table 1), KyActin1 gene primers. 18S rRNA, KyActin1 gene as an internal control, the test results were processed. The PCR reaction was performed on an OPTION 2 fluorescence quantitative PCR machine.

Table 1. Primer sequences of real time quantitative RT-PCR

\begin{tabular}{|c|c|c|c|c|}
\hline Gene name & & Sequence of pnimer & $\begin{array}{l}\text { Expected size of } \\
\text { PCRproducts }\end{array}$ & $\begin{array}{c}\text { NCBI } \\
\text { Accession number }\end{array}$ \\
\hline$P A L$ & $\begin{array}{l}\text { Sense } \\
\text { Antisense }\end{array}$ & $\begin{array}{l}\text { 5' CCGCTGAACTGGGGAATG 3' } \\
\text { 5' CACCGAGCCGAACAACCG 3' }\end{array}$ & 103bp & AB015870 \\
\hline CHS3 & $\begin{array}{l}\text { Sense } \\
\text { Antisense }\end{array}$ & $\begin{array}{l}\text { 5' TCGGCTGAGGAAGGGCTGAA 3' } \\
\text { 5' GGCAAGTAAAGTGGAAACAG 3', }\end{array}$ & 152bp & AB066274 \\
\hline CHI1 & $\begin{array}{l}\text { Sense } \\
\text { Antisense }\end{array}$ & $\begin{array}{l}\text { 5' CAGGCAACTCCATTCTTTTC 3’'} \\
\text { 5' TTCTCTATCACTGCATTCCC 3' }\end{array}$ & 103bp & X75963 \\
\hline F3H2 & $\begin{array}{l}\text { Sense } \\
\text { Antisense }\end{array}$ & $\begin{array}{l}\text { 5' TCATCCGCACCACACCATG 3' } \\
\text { 5' AGTTGGCGTCGTGGGTGC 3' }\end{array}$ & 137bp & DQ787856 \\
\hline$F 3^{\prime} H$ & $\begin{array}{l}\text { Sense } \\
\text { Antisense }\end{array}$ & $\begin{array}{l}\text { 5' GCCTCCGTTGCTGCTCAGTT } \\
\text { 5' GAGAAGAGGTGGACGGAGCAAATC }\end{array}$ & 132bp & AB113261 \\
\hline F3'5'H & $\begin{array}{l}\text { Sense } \\
\text { Antisense }\end{array}$ & $\begin{array}{l}\text { 5' AAACCGCTCAGACCAAAACC } \\
\text { 5' ACTAAGCCACAGGAAACTAA }\end{array}$ & 118bp & AB213606 \\
\hline DFR & $\begin{array}{l}\text { Sense } \\
\text { Antisense }\end{array}$ & $\begin{array}{l}\text { 5' GAAACCTGTAGATGGCAGGA 3', } \\
\text { 5' GGCCAAATCAAACTACCAGA 3' }\end{array}$ & 111bp & X75964 \\
\hline$L D O X$ & $\begin{array}{l}\text { Sense } \\
\text { Antisense }\end{array}$ & $\begin{array}{l}\text { 5' AGGGAAGGGAAAACAAGTAG 3' } \\
\text { 5' }^{\prime} \text { ACTCTTTGGGGATTGACTGG 3' }\end{array}$ & 109bp & X75966 \\
\hline$U F G T$ & $\begin{array}{l}\text { Sense } \\
\text { Antisense }\end{array}$ & $\begin{array}{ll}\text { 5' } & \text { GGGATGGTAATGGCTGTGG 3' } \\
5^{\prime} & \text { ACATGGGTGGAGAGTGAGTT 3' }\end{array}$ & 152bp & AF000372 \\
\hline OMT & $\begin{array}{c}\text { Sense } \\
\text { Antisense }\end{array}$ & $\begin{array}{l}\text { 5' CCATAAGCAAACCCTAAACC3' } \\
\text { 5' TGAACAAATTCTTGGCATCA 3' }\end{array}$ & 128bp & BQ796057 \\
\hline GST & $\begin{array}{l}\text { Sense } \\
\text { Antisense }\end{array}$ & $\begin{array}{l}\text { 5' ACTTGGTGAAGGAAGCAGGA 3', } \\
\text { 5' CAGCGAGCTCCATGACTTTT 3', }\end{array}$ & 114bp & BQ796591 \\
\hline $4 C L$ & $\begin{array}{l}\text { Sense } \\
\text { Antisense }\end{array}$ & $\begin{array}{lll}\text { 5' } & \text { GAGTTTAGTTCTCGTCCC } & 3{ }^{\prime} \\
5^{\prime} & \text { GCGCCCATAAAAGCAAAC } \quad 3^{\prime}\end{array}$ & 182bp & NTU50845 \\
\hline $\mathrm{C} 4 \mathrm{H}$ & $\begin{array}{l}\text { Sense } \\
\text { Antisense }\end{array}$ & $\begin{array}{l}5^{\prime} \text { CGTAGCGATTGCTGTTTC } 3 \\
\text { 5' GAAACGACGACGAGATTG } \quad 3^{\prime}\end{array}$ & 192bp & AF548370 \\
\hline$A C T$ & $\begin{array}{l}\text { Sense } \\
\text { Antisense }\end{array}$ & $\begin{array}{l}\text { 5' TACCACCAGAAAACTCCC } \quad 3 ' \\
\text { 5' CTTCCAAGTAAATAACCC } \quad 3 '\end{array}$ & 162 bp & EU 979541 \\
\hline$R S$ & $\begin{array}{l}\text { Sense } \\
\text { Antisense }\end{array}$ & $\begin{array}{lll}5^{\prime} & \text { TGGTGCTTATATGGCTCC } & 3^{\prime} \\
5^{\prime} & \text { CGAGTTTGTAATCCGCAC } & 3^{\prime}\end{array}$ & 185bp & AF274281 \\
\hline ANR & $\begin{array}{l}\text { Sense } \\
\text { Antisense }\end{array}$ & $\begin{array}{l}\text { 5' CAATACCAGTGTTCCTGAGC 3' } \\
\text { 5' AAACTGAACCCСTCTTTCAC 3' }\end{array}$ & 141bp & AY641729 \\
\hline $18 S r R N A$ & $\begin{array}{l}\text { Sense } \\
\text { Antisense }\end{array}$ & $\begin{array}{l}\text { 5' CTTTGCCGCTTGCTCTGATG 3' } \\
\text { 5' TGCTGCCTTCCTTGGTTGTG 3' }\end{array}$ & 266bp & BE846404 \\
\hline KyActin1 & $\begin{array}{l}\text { Sense } \\
\text { Antisense }\end{array}$ & $\begin{array}{l}\text { 5' GATTCTGGTGATG GTGTGAGT 3' } \\
\text { 5' GACAATTTCCCGTTCAGCAGT 3' }\end{array}$ & 168bp & AB073011 \\
\hline
\end{tabular}


By calculating the 2- $\Delta \Delta \mathrm{Ct}$ value to determine the relative gene expression in different periods [3]. After eliminating the background fluorescence of SYBR Green I, the best Ct value was determined. The average $\mathrm{Ct}$ values (including the target gene and the internal standard gene) of 3 replicates for each reaction were averaged. The difference ( $\Delta \mathrm{Ct}$ value) between the mean $\mathrm{Ct}$ value of the target gene and the average Ct value of the internal standard genes 18S rRNA and KyActin1 was calculated by subtracting the $\Delta \mathrm{Ct}$ of the control sample (fifth period) from the $\Delta \mathrm{Ct}$ value of each test sample There is a linear relationship between the $\Delta \mathrm{Ct}$ value of each template and the logarithm of the initial copy number of the template. The more the initial copy number, the smaller the Ct value. Therefore, the relative expression level of the gene at different times was determined by $2-\Delta \Delta \mathrm{Ct}$ value.

\section{Results and Analysis}

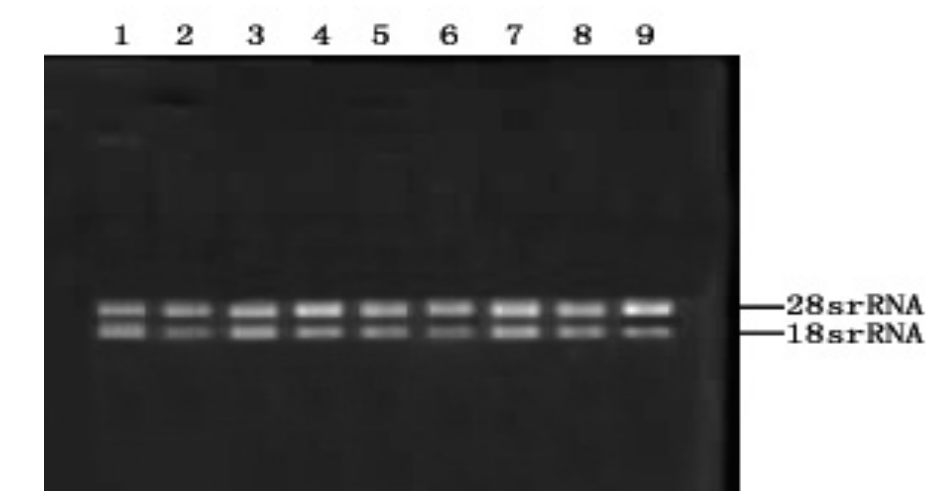

Fig 1. Agarose gel electrophoreis of total RNA from skin of Vitis.

The extracted total RNA was digested with RQ1 RNase-Free DNase to eliminate possible DNA contamination. Total RNA was tested for concentration and purity by UV spectrophotometer and $1 \%$ agarose gel electrophoresis. As shown in Fig 1, the total RNA extracted was measured for its UV absorbance by a nucleic acid analyzer with an OD260 / 280 of more than 1.98 and an OD260 / 230 of more than 2.00, indicating that the purity of the obtained RNA was high and that $1 \%$ agarose gel electrophoresis The results showed that the bands of 28srRNA and 18s rRNA were clear and the brightness ratio was close to 2: 1 . There was no genomic DNA, indicating that the total RNA was not degraded completely and its purity and integrity were in accordance with qRT-PCR.

The qRT-PCR technique was used to analyze the expression of 12 enzymes in the peel of grapevine. As can be seen from Fig 2, PAL was down-regulated before turning 2 weeks after flowering, the expression decreased, and the expression level was the lowest at 8 weeks after flowering, Expression, with the deepening of fruit coloring, enhanced expression, color to mature expression level difference was not significant, the highest expression level when the fruit mature. Chalcone synthase (CHS3) was downregulated before 2 weeks after flowering, the expression decreased, and the expression was lowest at 8 weeks after flowering. The expression of chalcone synthase (CHS3) was up-regulated after transfection. With the deepening of fruit coloration, Enhanced expression, the highest level of expression when the fruit is mature. The chalcone isomerase (CHI1) expression decreased from 2 weeks to 8 weeks after anthesis, and reached its peak at 8 weeks after anthesis. The expression was up-regulated from 2 weeks to 4 weeks after anthesis, and down-regulated from 6 weeks to 8 weeks after anthesis. Tricolor to maturity as up-regulated expression, mature expression of the highest. The expression of flavanone 3-hydroxylase (F3H2) decreased from the second week to the eighth week after anthesis, and increased from 8 weeks after anthesis to maturity, with the highest expression level at maturity. The expression was up-regulated at 2 weeks after flowering, down-regulated at 4 weeks after flowering, and turned up to mature at 4 weeks after flowering. Mature always showed an upward trend, rising rapidly from 50\% pigmentation maturity and highest expression in mature period. Flavonol 4-reductase (DFR) decreased from 2 weeks to 6 weeks after anthesis, and increased from 6 weeks to 
8 weeks after anthesis, and then decreased from 8 weeks after anthesis to color change to mature expression Strengthen the expression level of the two weeks and the maturity after anthesis basically the same. At 2 weeks to 4 weeks after flowering, the expression was up-regulated, down-regulated at 6 weeks, and up-regulated at 8 weeks after flowering. After 2 weeks and 8 weeks of flowering, the expression of colorless flower anthocyanidyl-dioxygenase (LDOX) showed a decreasing trend, and then the expression began to strengthen, and the expression decreased after $50 \%$ staining. After 2 weeks to 4 weeks after flowering, the expression was strong and up-regulated, down-regulated from 6 to 8 weeks after flowering, and turned up to mature after transformation. The UDP-glucose-flavonoid 3-O-glucosyltransferase (UFGT) was down-regulated from 2 weeks after anthesis to anthesis, and turned up to maturity and up-regulated. Before the color change is always at a low level of expression, color to mature expression is on the rise, the strongest expression at maturity. O-methyltransferase (OMT) is down-regulated before transfection, and turned to mature to up-regulated expression. Before the color change is always at a low level of expression, color to mature expression is on the rise, the strongest expression at maturity. Glutathione S-transferase (GST) was down-regulated before transfection, and its expression level was very low. It was up-regulated from color change to maturity, and the expression was up-regulated. The expression was the strongest at maturity. Anthocyanidin reductase (ANR) was up-regulated from 2 weeks after anthesis to decolorization stage, and the expression decreased. 2 weeks after anthesis to 6 drops quickly.
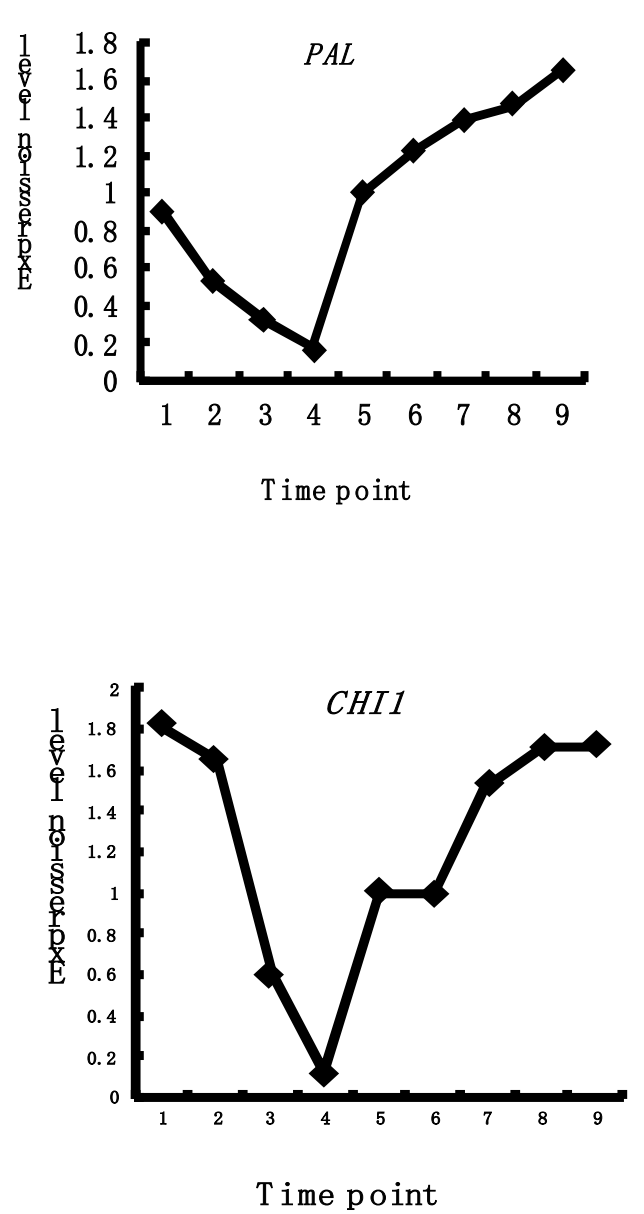
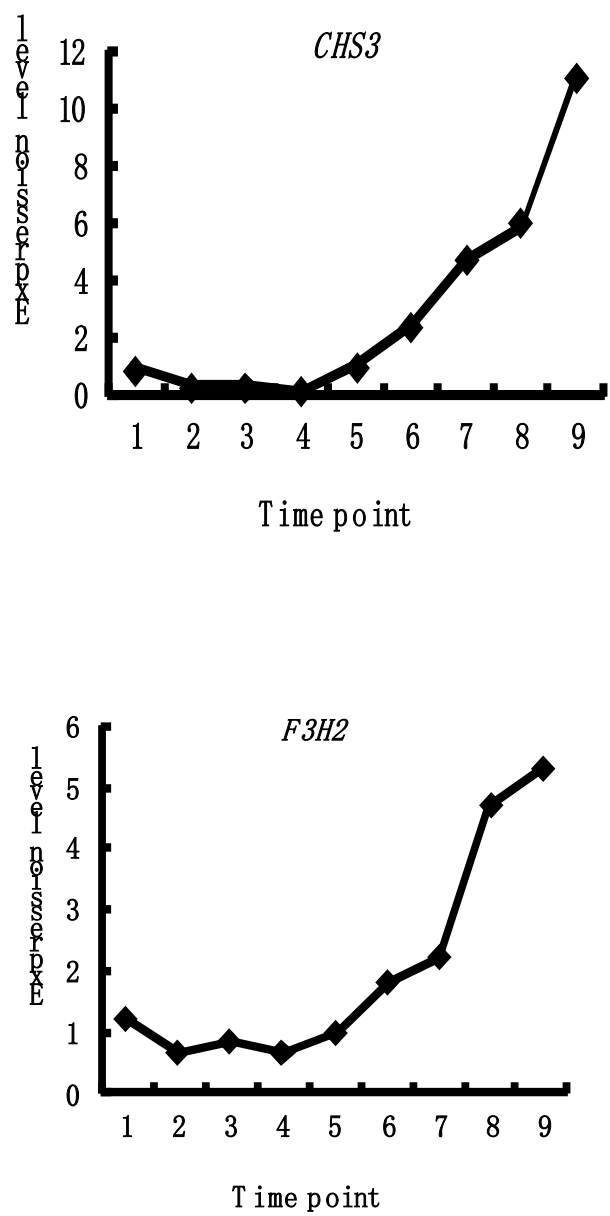

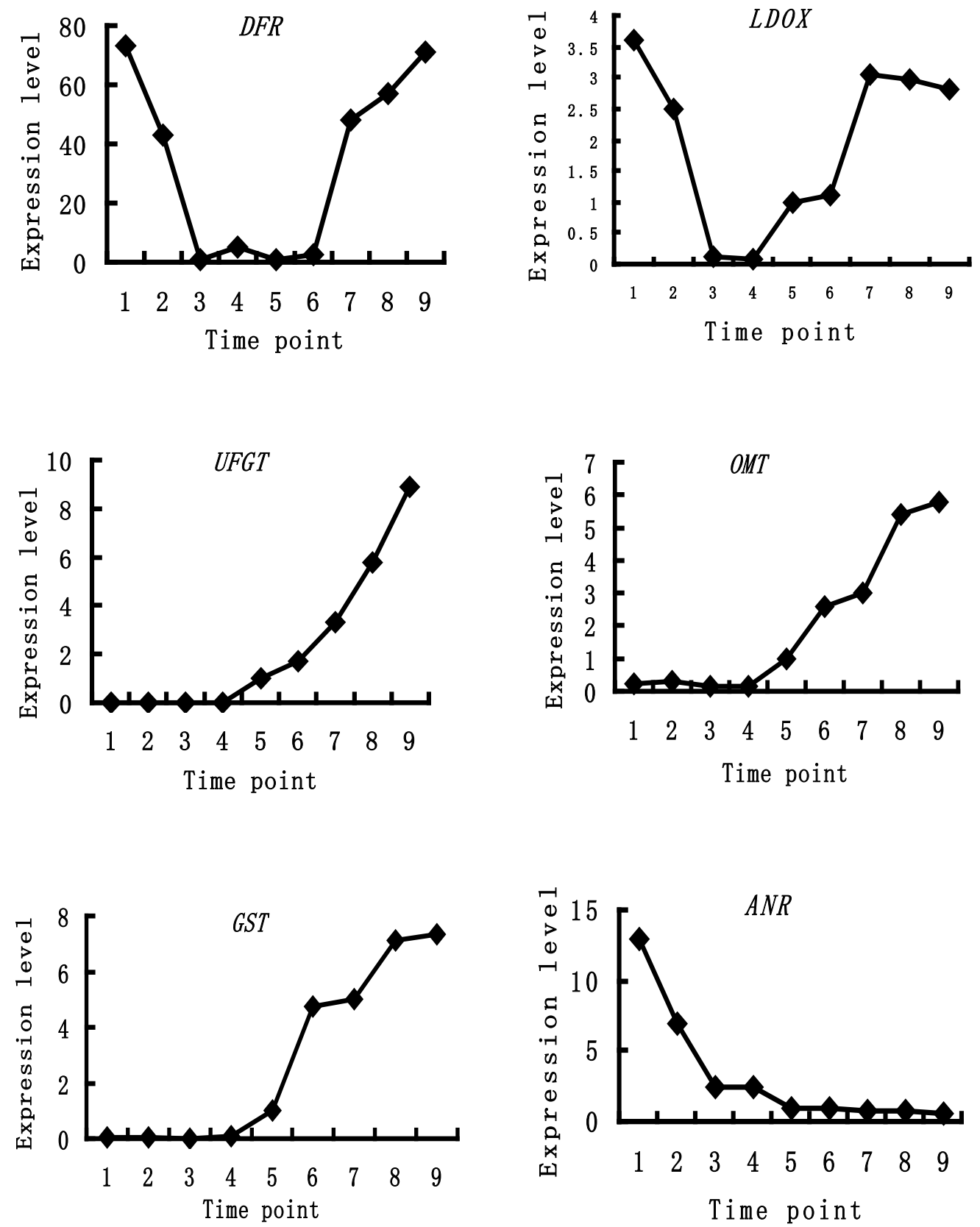

Fig 2. Gene expression patterns of Vitis Skin in 9 of stages.

Note: The X-axes shows growth time points and Y-axes shows gene expression level.

\section{Conclusions}

In this study, real-time quantitative PCR was used to study the expression pattern of 10 enzyme genes in the grapevine peel at different growth stages. PAL showed the strongest expression in grape fruits at 2 weeks after anthesis, then decreased gradually and stabilized until the color conversion period of fruits [4-5]. PAL activity rose sharply after maturity and decreased to Lower level [6]. CHS is strongly expressed on mature peels of red cultivars, while weakly expressed or not expressed on white cultivars [7-9]. During the development of red grape, CHS had the strongest expression on the fruit two weeks after anthesis, decreased to the lowest level before the color change and slowly increased after the transitional period [10-12]. During the fruit development of red grape, CHI was mainly expressed on the pericarp of 2-4 weeks after anthesis, then its expression 
was weakened. With the enhancement of coloration of fruit, the expression of CHI was unchanged at 4 weeks after anthesis. F3H2 was mainly expressed on the pericarp of 2-4 weeks after flowering in the fruit development of red grape, then its expression was weakened, the color of the fruit was up-regulated during the color-changing period and was down-regulated in the pericarp after the color-changing period [14-15]. During the development of the red grape fruit, the DFRs were most strongly expressed on the pericarps 2-4 weeks after anthesis, and then weakened, with the enhancement of coloration of the fruit [16]. During the development of red grape fruit, LDOX was the strongest on the pericarp of 2-4 weeks after anthesis, then weakened, with the enhancement of coloration of the fruit [17-18]. Under natural conditions, UFGT was expressed only on the pericarp of the red grapes during the color change period, not on the white cultivars and flesh, and was up-regulated during the color-changing period, with enhanced expression of fruit ripening [19]. OMT was basically not expressed before the fruit was transferred, the expression was up-regulated during the color change period, and the expression level on the colored peel was significantly higher than that on the uncolored peel [18-20]. The expression of GST was up-regulated in the fruit of the grape during the color change period. The expression of the fruit before the color change was very low. After entering the color change period, the GST was transcribed in large quantities. The expression of GST was higher in the flesh of the red-skinned red meat, almost no expression. Bogs et al. Studied the expression of ANR in grapes. ANR was expressed in leaves, flowers and fruits, and the proanthocyanidins also increased with the growth of leaves, flowers and fruits. However, when the fruit matured, the ANR gene not expressed in the fruit, procyanidins no longer increase [20].

\section{References}

[1] Yang Chengjun, Wang Jun. Construction of cDNA library of ginseng leaves from red ginseng [J]. Proce Physiology of Communications. 2007, 38 (4): 664-668.

[2] Wen Pengfei. Grape and wine flavanols polyphenols and fruit proanthocyanidin synthesis enzymes related research [D]. Beijing: China Agricultural University. 2005, 77-79.

[3] Zhang B, Chen K, Bowen J, et al. Differential exepression within the LOX gene family in ripening kiwifruit J. J Exp Bot, 2006, 57 (14): 3825-3836.

[4] Yu Shuwen, Tang Zhangcheng. Plant Physiology and Molecular Biology [M]. Beijing: Science Press, $390 \sim$ 399,770 806.

[5] Waters DLE, Holton TA, Ablett EM, Lee LS, Henry RJ (2005). CDNA microarray analysis of development grape (Vitis vinifera cv. Shiraz) berry skin. Functional \& Integrative Genomics, 5: 40-58.

[6] Chen JY, Wen PF, Kong WF, Pan QH, Wan SB, Huang WD (2006). Changes and subcellular localizations of the enzymes involved in phenylpropanoid metabolism during grape berry development. Journal of Plant Physiology 163: 115-127.

[7] Tropf S, Lanz T, Rensing SA, Schroder J, Schroder G (1994). Evidence that stilbene synthases have been developed from chalcone synthases several times in the course of evolution. Journal of Molecular Evolution, 38: 610- 618.

[8] Boss PK, Davies C, Robinson SP (1996b). Expression of anthocyanin biosynthesis pathway genes in red and white grapes. Plant Molecular Biology 32: 565-569.

[9] Kobayashi S, Ishimaru M, Hiraoka K, Honda C (2002). Myb-related genes of the Kyoho grape (Vitis labruscana) regulate anthocyanin biosynthesis. Planta, 215: 924-933.

[10] Boss PK, Davies C, Robinson SP (1996a). Analysis of the expression of anthocyanin pathway genes in developing Vitis vinifera L. cV Shiraz grape berries and the implications for pathway regulation. Plant Physiology, 111: 1059-1066. 
[11] Kobayashi S, Ishimaru M, Ding CK, Yakushiji H, Goto N (2001). Comparison of UDP-glucose: flavonoid 3-O- glucosyltransferase (UFGT) gene sequences between white grapes (Vitis vinifera) and their sports with red skin. Plant Science, 160: 543-550.

[12] Sparvoli F, Martin C, Scienza A, Gavazzi G, Tonelli C (1994). Cloning and molecular analysis of structural genes involved in flavonoid and stilbene biosynthesis in grape (Vitis vinifera L.). Plant Molecular Biology 24: 743 755.

[13] Da Silva FG, Iandolino A, Al-Kayal F, Bohlmann MC, Cushman MA, Lim H, Ergul A, Figueroa R, Kabuloglu EK, Osborne C, Rowe J, Tattersall E, Leslie A, Xu J, Baek JM , Cramer GR, Cushman JC, Cook DR (2005). Characterizing the grape transcriptome. Analysis of expressed sequence tags from multiple Vitis Species and development of a compendium of gene expression during berry development. Plant Physiogy, 139: 574-597.

[14] Holton TA, Cornish EC (1995). Genetics and biochemistry of anthocyanin biosynthesis. Plant Cell, 7: 1071-1083.

[15] Dixon RA, Steele CL (1999). Flavonoids and isoflavonoids - a gold mine for metabolic engineering. Trends in Plant Science, 4: 394-400.

[16] Koes R, Verweij W, Quattrocchio F (2005). Flavonoids: a colorful model for the regulation and evolution of biochemical pathways. Trends in Plant Science, 10 (5): 236-242.

[17] Castellarini SD, Matthews MA, Gaspero GD, Gambetta GA (2007a). Water deficits accelerate ripening and induce changes in gene expression regulating flavonoid biosynthesis in grape berries. Planta (online), DOI 10.1007 / s00425-007-0598 18.

[18] Castellarini SD, Pfeiffer A, Silvilotti P, Degan M, Peterlunger E, Gaspero GD (2007b). Transcriptional regulation of anthocyanin biosynthesis in ripening fruits of grapevine under seasonal water deficit. Plant, Cell and Environment, 30: 1381-1399.

[19] Jeong ST, Goto-Yamamoto N, Hashizume K, Esaka M (2006). Expression of the flavonoid 3'-hydroxylase and flavonoid 3 ', 5'-hydroxylase genes and flavonoid composition in grape (Vitis vinifera), 170: $61 \sim 69$.

[20] Ageorges A, Fernandez L, Vialet S, Merdinoglu D, Terrier N, Romieu C (2006). Flow specific isogenes of the anthocyanin metabolic pathway are systematically co-expressed with the red color of grape berries. Plant Science, 170: $372 \sim 383$. 